\title{
How to Carry Out Bathymetric and Elevation Surveys on a Tight Budget: Basic Surveying Techniques for Sustainability Scientists
}

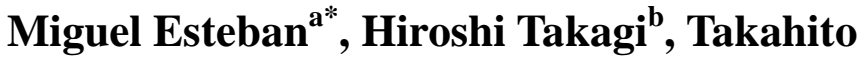 \\ Mikami $^{\mathrm{c}}$, Lama Bahbouh ${ }^{\mathrm{c}}$, Austin Becker ${ }^{\mathrm{e}}$, \\ Leonard Nurse ${ }^{f}$, Tomoya Shibayama ${ }^{c}$, \\ Mohammad Nagdeef.
}

${ }^{a}$ Graduation Program in Sustainability Science, Global Leadership Initiative (GPSS-GLI), The University of Tokyo, Tokyo, Japan

${ }^{b}$ Tokyo Institute of Technolgy, Tokyo, Japan

${ }^{c}$ Tokyo City University, Tokyo, Japan

${ }^{d}$ Department of Civil \& Environmental Engineering, Waseda University, Tokyo, Japan

${ }^{e}$ Coastal Institute, University of Rhode Island, USA

${ }^{f}$ University of the West Indies, Barbados ${ }^{f}$

Received: November 6, 2017/ Accepted: November 20, 2017

\begin{abstract}
Sustainability scientists often face a difficult task to conduct research or carry out preliminary investigations around coastal areas in developing countries, due to the limitation in the availability of topographical and bathymetry data. These limitations can be particularly important for the case of ports, on which the livelihoods of many fishing communities depend on. Often, cost is cited as a reason regarding the absence of any such data. However, in the present technical note the authors highlight how existing "low-level" surveying methods can be inexpensive and allow sustainability scientists to conduct a reasonably accurate survey for less than 1,00o USD, provided that researchers possess a reasonable knowledge of mathematics and geometry (high-school equivalent).
\end{abstract}

Keywords: Typhoon Yolanda; Awareness; Preparedness; Resilience; Evacuation Preparations

\section{Introduction}

With $80 \%$ of world trade being carried by sea, seaports represent crucial linkages in global supply-chains (UNCTAD 1992). However, seaports are likely to be affected directly and indirectly by climatic changes, and are particularly vulnerable to extreme weather events associated with increasing sea levels and tropical storm activity surges (Hanson and Nicholls 2012; Asariotis and Benamara 2012, service disruptions alone can cause total economic losses in the billions of euros/dollars, see Haveman and Shatz 2006; Lloyds Loading List 2012). The coastal or estuarine location of seaports suggests that mean sea level (MSL) rise, higher storm surges and river floods or droughts (Tebaldi et al. 2012; Von Storch et al. 2008), increased cyclone intensities/destructiveness (Knutson et al., 2010, Nakamura et al., 2016) and potential changes in wave regimes (Mori et al., 2010) could cause expensive operational delays (Esteban et al., 2009). Recent global projections suggest sea levels could rise by as much as 1.9 meters by 2100 (Vermeer and Rahmstorf 2009), which would exacerbate wave damage to breakwaters and other installations (Esteban et al., 2014). Some regions will find the local MSL rise greater than the global mean, causing additional impacts ranging from business losses to catastrophic disasters (Esteban et al. 2010; Hallegatte et al. 2011).

The long lifetime of port assets, many of which were designed for a different climatic regime (USCCSP 2008), could result in infrastructure being ' under-designed' for future climate conditions. Due to their strategic role as part of the global trading system, adapting ports (either through "soft" or "hard" adaptation strategies) in different parts of the world to the impacts of climate change is of great importance, and will require collaboration and support from a broad range of public and private sector stakeholders (Becker et al., 2013). The established approaches to planning and decision making currently appear to be inappropriate due to the long time frames of climate impacts and short portplanning horizons, the lack of engineering and design standards to guide decision makers in light of the changing climate, and the lack of adequate data and of institutional arrangements to address regional and local climate effects (Becker et al., 2013).

Particularly, the lack of data can make it difficult for disaster risk managers, sustainability scientists and other stakeholders to carry out surveys around ports. While accurate surveys are often carried out during the design and initial planning process for any new developments, there is often a need for some sort of data to be available during the "pre-planning", "research" or "conceptualization" stages for which funding is often limited. This problem can be particularly severe for the case of developing countries, where sometimes ports authorities do not even have information regarding the elevation of the port with respect to sea levels. During a UNCTAD expert level meeting on "Climate Change impacts and Adaptation for Coastal Transport Infrastructure in Caribbean SIDS" held between the 29th and 1st of July 2016 a number of participants highlighted how it is often difficult to obtain elevation and bathymetry data from port authorities. One of the reasons cited was that port authorities, particularly in developing countries, often had little or no data regarding bathymetry or elevation above sea level of their installations. As a result of the above mentioned UNCTAD meeting, the authors were invited to submit some technical guidance to the PIANC technical guidance report on climate change adaptation for port and navigation infrastructure (also known as "Working Group 178" of PIANC). Although such problems are often attributed to a lack of resources (given the expertise and expense involved in carrying out 
a professional survey of installations), present day technology allows for a decent level of accuracy to be achieved when carrying out simple topographic and bathymetric surveys, with a very modest financial investment in equipment. Essentially, the use of some relatively cheap equipment, some ingenuity and common sense, and a relatively modest level of training should allow almost any port to conduct a preliminary survey of its installations and bathymetry. Such initial "rough" surveys can later be refined based on more detailed surveys.

In the present technical note, the authors argue that surveying exercises can be carried out by even financially challenged ports in developing countries. To do so, it would be necessary for the port to invest around 500-1,000 USD in equipment, and that they have some staff with a decent understanding of geometry and maths (high-school level or equivalent) and a small boat. In doing so the authors are not claiming that such exercises are a substitute for a detailed topographical or bathymetric survey of an area carried out by surveying professionals. Rather, when faced with budget and expertise constraints, the methods outlined in the present technical note can help port authorities obtain a fairly accurate picture of the elevation of their installations and bathymetry surrounding the port. In fact, these methods can be extrapolated and be used by sustainability scientists in a variety of coastal locations, and be used to conduct rough mapping of coastal settlements and other components of human socio-economic systems (including infrastructure, fields, etc). None of the methods that are outlined below are new (in fact, the entire point of this technical note is that they are all readily available and easy to use). Instead, the authors argue that the combination of very readily available and low-tech (by present day standards) methods can allow sustainability scientists to conduct a rough survey of the bathymetry and elevation of coastal areas. Sustainability science is often considered to be a science that adopts methodologies from a number of other subject disciplines, and in essence this technical note attempts to describe how simple surveying techniques can be used by any sustainability science practitioner, with minimum effort and cost.

\section{Methodology}

\subsection{Latitude and Longitude Measurements}

Determining the precise latitude and longitude of a point can be easily accomplished using modern GPS devices. While these have come down in price considerably (and the latest models, with a multitude of options, can be purchased for 40-50 USD), there are also a number of freeware applications that can accurately pinpoint the location of a smartphone or tablet. This effectively lowers the cost of determining the exact location of a certain point to the cost of a smartphone, which most people in developed (and even developing) countries have in their own pocket. Examples of freeware Apps for the case of iPhones include "GPS Receiver HD" and "Coordinates", and "GPS" Test for the Android operating system. Otherwise, establishing physical grids can increase the accuracy of surveys, and an example of how this can be done for the case of bathymetric surveys will be explained later.

The accuracy of GPS measurements using smartphones or GPS systems depends on the type of GPS receiver and chipset in each device and the number of satellites in view. Most smartphones can have an accuracy of around 1om in the horizontal direction (though can be as low as around $5 \mathrm{~m}$ ). With regards to vertical elevation, accuracy can be three times lower (as much as 30m), obviously rendering their use for low-lying ports meaningless.

\subsection{Bathymetric measurements}

Modern bathymetric surveys use expensive equipment, such as echosounders or LIDAR systems. However, traditional ways of conducting bathymetric surveys involved the use of a rope and a heavy weight attached to the bottom of it, lowered from the side of a boat. While the accuracy of such methods in previous times was questionable (as the position of the boat could not be known with accuracy, especially given the influence of waves and currents), the existence of modern GPS systems allows for more precise bathymetric surveys to be made, even using such a rudimentary method as a "rope and lead" (for deeper water, over 10m) or even just a surveying rod (for shallow water, less than 5-10m in depth, as surveying rods are typically 5 to $10 \mathrm{~m}$ long, see Fig. 1).

For the case of the "rope and lead" method, it would be necessary also to first measure and mark the rope appropriately, so that the surveyor would automatically know the length of the rope submerged into the water. Essentially, the surveyor ties a heavy object ("lead") to the bottom of the rope, and lowers it into the water until it becomes slack, recording the length of the rope underwater. Problems with this "rope and lead" include the possibility that the rope might not travel straight to the floor, mainly due to the existence of underwater currents. Thus, the level of inaccuracy is likely to increase with depth, and different weather effects, temperature, etc, are likely to have an effect on the accuracy of the measurement. Where more precise measurements are required, or where there is a layer of soft sediment in the bottom of the sea (which can make it difficult for a human to feel when the rod or lead hits the bottom) a sensor can be attached to the "lead" to improve accuracy (which can cost around 300-500 USD, see Fig. 2). Otherwise, a portable echo sounder can be bought for between 40-500 USD, which often nowadays come with a GPS (see Fig. 3). This can significantly increase the speed of measurements and possibly reduce the overall costs.

Hiring a small boat would allow a team of 2 or 3 members to conduct point measurements of the bathymetry of the port basin and even the area outside it. One member would be placing the surveying rod or rope (with the lead attached to it) to measure the depth of the water. Another would operate a GPS or smartphone with relevant software and take recordings of the latitude, longitude and depth. Prior to the beginning of the survey the number of points to be surveyed should be determined with the aid of charts and/or instruments such as Google Earth, which would allow somebody to roughly determine the approximate location and number of points to be surveyed. Given that it can be difficult for a boat captain to keep the location long enough to take appropriate measurements, the use of a float line is recommended. The float line is anchored onshore with a steel peg and the other end of the line is attached to a floating buoy that has been oriented perpendicular to the onshore anchor point using an optical square. The small boat would simply follow the fixed float line and take a depth reading at every $5 \mathrm{~m}$ or $10 \mathrm{~m}$ interval (see above figure). This would be repeated for subsequent perpendicular lines anchored at $5 \mathrm{~m}$ or $10 \mathrm{~m}$ intervals along the shore (see Fig. 4)

When deciding on the density of the points to be surveyed, it is worth keeping in mind that when establishing bathymetric grids for simulations a good grid size for a part is considered to be 5 to 10m, which would allow the investigation of the properties of wind waves in port behind breakwaters, where bathymetry would have a great influence on reflection, refraction or surf beat. Also, such detailed grids can be important for the estimation of dredging purposes. For the wider area outside the port, however, less detailed grids are typically employed, and a zom grid would be fine with the 
simulation of tsunamis and storm surges. However, it is also worth noting that, for preliminary investigation purposes, the collection of any data is better than having no data, so even higher grid sizes (10om) can be of use during research phases or preliminary design (some data is better than no data principle).

The total cost of such a survey would be limited (around maybe 50-10o USD for a surveying rod, 40 USD for a 30 metre nylon float line with swivel and hook, and 35-65 USD for a simple optical square, plus the rental of a boat, if the port in question did not have one to start with). Nevertheless, it is worth noting that in many developing countries the cost of hiring a small fishing boat for a few days is inexpensive.

The accuracy of bathymetric surveys using a surveying staff is probably in the order of $+/-5 \mathrm{~cm}$ (given that there might be a layer of mud or some other small feature of terrain at the point being surveyed). The accuracy of a "rope and lead" method might be lower, possibly up to $+/-1 \mathrm{~m}$. Nevertheless, it is worth noting that even in such cases the existence of any measurements would greatly help a coastal engineer verify publicly available data (such as that from GEBCO (General Bathymetric Chart of the Oceans, http://www.gebco.net/) and

ETOPO (https://www.ngdc.noaa.gov/mgg/global/global.html)) and greatly improve the accuracy of the simulation.

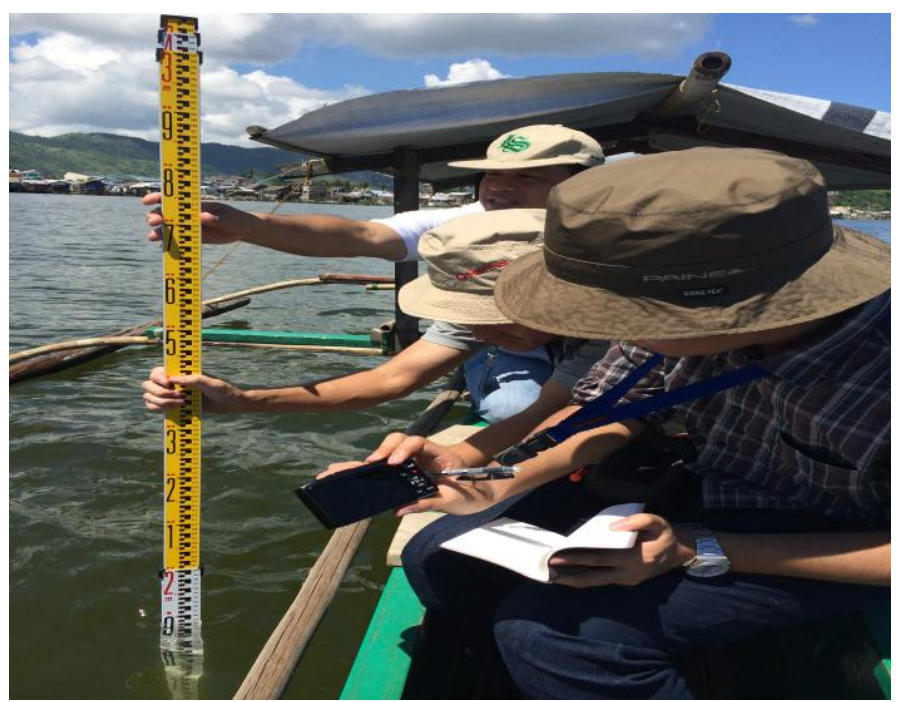

Figure 1 Use of surveying rods to conduct rudimentary bathymetric surveys

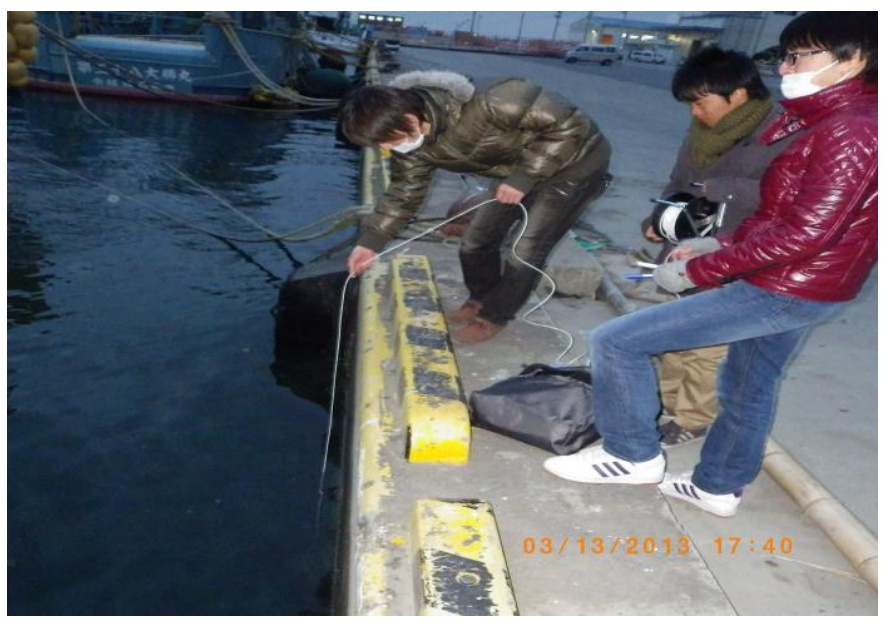

Figure 2 Rope with sensor attached to it to determine water depth

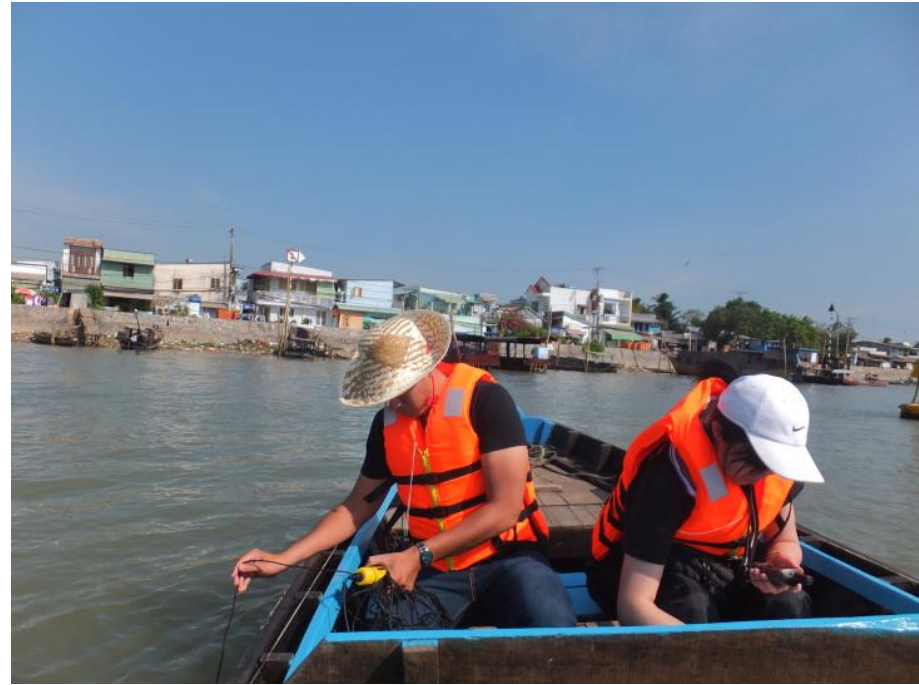

Figure 3 Use of portable echo sounder

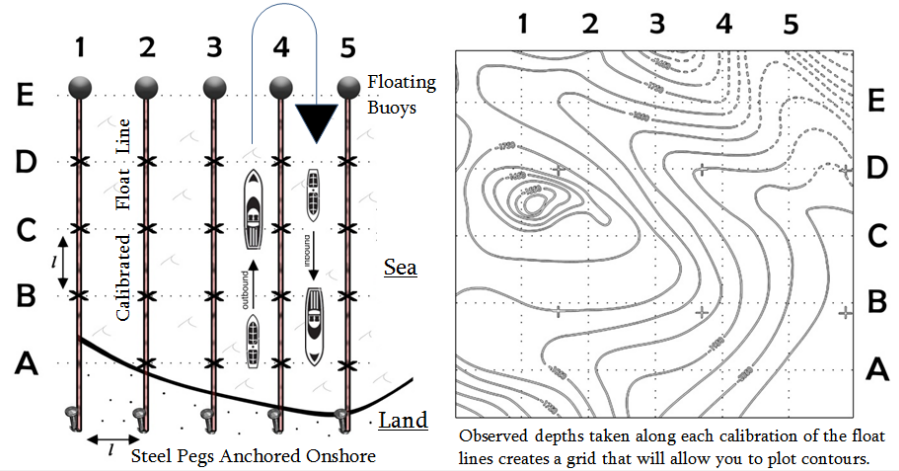

Figure 4 Procedure to conduct bathymetric surveys using a float line

\subsection{Land Surveys}

Rudimentary distance and elevation topographical surveys can be conducted with the help of hand-held laser distance meters. The more basic models have a price as low as 200 USD (the authors have experience using those produced by Leica, Topcon, Sokkia) and a surveying rod and prism (which can be bought for around 200 USD, see Fig. 5). It is likely that every port authority has at least a rudimentary map of the area under its authority. If not, a rough outline of the area to be surveyed can be found from free software such as Google Earth (which is also able to provide the coordinates of any point selected). This map should form the starting point of any survey. 


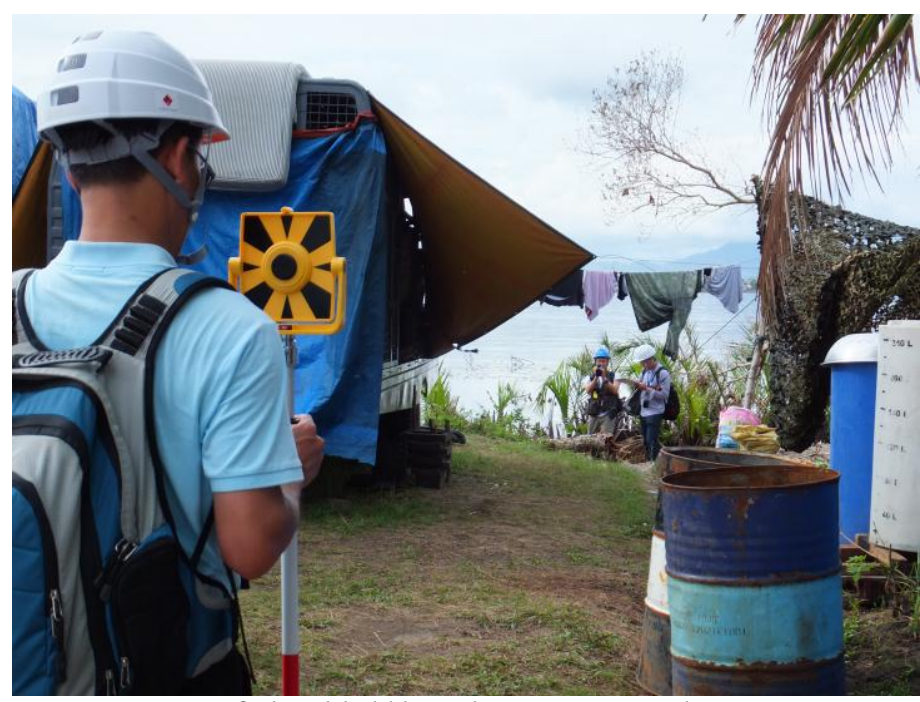

Figure 5 Use of a hand-held laser distance meter and target prism to conduct land surveys

The first point to be surveyed should be that at the surface/sea boundary. If a beach is present, then the first point to be measured should be the water mark (by placing the prism rod or surveying staff exactly at the edge between the water and the sand, see Fig. 6 and 7 ). If the survey is to be conducted at a wharf, then the distance from the surface of the wharf to the top of the water should be measured using a surveying staff.

Once the elevation of the starting point (essentially zero in the case when the survey starts at a beach, or otherwise the elevation of the wharf) is recorded, the survey can then continue by measuring the elevation and distance of subsequent points with regards to this starting point (see Fig. 8 and the example later in this technical note). It is crucial that every measurement is repeated at least 3 times, in order to verify the accuracy of each reading. Care must be taken to also record the coordinates of every other position measured, in order to later be able to place each location on a map. By then taking measurements of points further away and using general logic it is possible to obtain a fairly accurate map of an area, including cross sectional profiles (see examples later).

In terms of accuracy, many laser range metres measure distances to an accuracy of o.1m (implying an error or up to $+/-5 \mathrm{~cm}$ per measurement). Thus, the accuracy of measurements will gradually decrease as the survey moves away from the sea. Nevertheless, given that the area of interest to port authorities and coastal engineers is that located closest to the sea, this would appear adequate for most purposes.

Measuring Ground Height
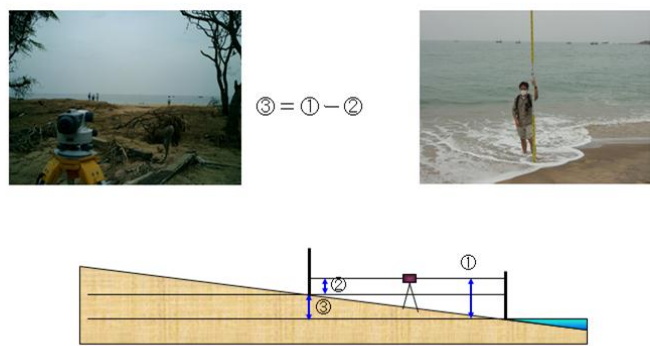

Figure 6 Measuring Procedure. All measurements should start from the waterline



Figure 7 Measuring Procedure using a tripod and staff

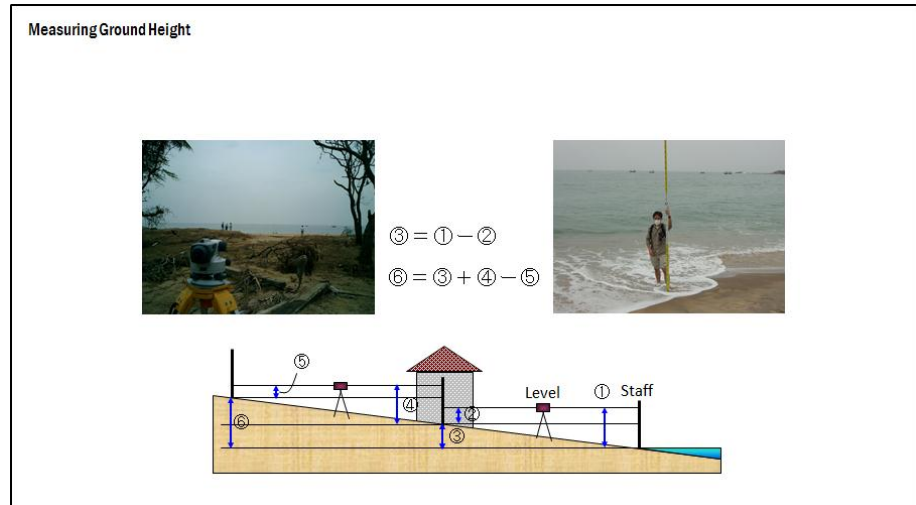

Figure 8 Measuring Procedure. Gradually the survey should move away from the sea

\subsection{Correcting for tide}

When conducting the surveys it is very important to record the exact time when the survey starts (i.e. when the survey starts at the edge of the sea), in order to later take into account tidal variations. Obviously, it is recommended that surveys take place on reasonably calms days, where there it is less likely that there are any windrelated changes in water level (wind set-up, etc), and avoid periods of heavy water discharge after heavy rain, if conducted close to river mouths. Tidal levels can easily be obtained by a coastal engineer using a range of software (for example Xtide), and corrections can be made for local surveying references levels.

\subsection{Example}

The authors of the survey have used the methodology outlined above on multiple occasions, and below is an example of a topographical survey carried out in three coastal barangays of Puerto Princesa, in the Philippines (Barangays are the smallest administrative unit in the Philippines, somehow equivalent to a neighborhood). The precise location of each survey point was first recorded by using GPS instruments, and then the elevation and distance to previous and successive points was surveyed using a laser ranging instrument (IMPULSE, Laser Technology Inc.) and a prism. Each survey started at the sea in order to measure the water level at the time, with all levels being corrected for the tide at the time of the survey (tide levels were calculated using the Xtide software). 
Table 1 shows an example of the points surveyed at Barangay Pagkaesa, with Fig. 9 showing a cross-sectional profile of what the land looks like (not to scale, though this could have easily been plotted using CAD software or fed into an inundation model, though this was not the purpose of that exercise). This example started at a beach, which the shown in Table 2 and Figure 10 started at the edge of a group of houses located on stilts).

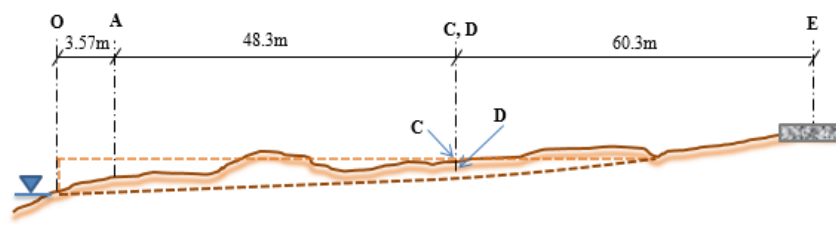

Figure 9 Elevation survey of informal settlement in Barangay Pagkaesa. Brown dashed lines indicated the level of houses on stilts. Dashed blue line indicated the rising profile of the water bed. Note diagram is not to scale.

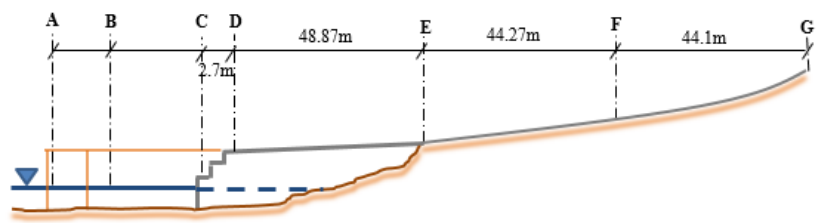

Figure 1o Diagrammatic elevation representation of informal settlement in Barangay Manderagat. Grey line indicates level of concrete walkway (points $C$ to $E$ ) and road (E to $G$ ). Note diagram is not to scale.

Table 1 Summary of surveyed points at Barangay Pagkaesa. Survey started at 11:10am on 16th March 2016

\begin{tabular}{|c|c|c|c|c|c|c|}
\hline $\begin{array}{l}\text { Poin } \\
t\end{array}$ & $\begin{array}{l}\text { Elevation } \\
(\mathrm{m}) \text { from } \\
\text { sea water } \\
\text { (measured } \\
\text { ) }\end{array}$ & $\begin{array}{l}\text { Elevatio } \\
\text { n }(\mathbf{m}) \\
\text { Correcte } \\
\text { d for tide } \\
\text { (Xtide) }\end{array}$ & $\begin{array}{l}\text { Elevatio } \\
\text { n (m) } \\
\text { Correcte } \\
\text { d for } \\
\text { Highest } \\
\text { High } \\
\text { Water } \\
\text { Level } \\
\text { (HHWL) }\end{array}$ & \multicolumn{2}{|c|}{$\begin{array}{l}\text { GPS } \\
\text { Coordinate } \\
\mathrm{s}\end{array}$} & Notes \\
\hline O & +0 & +0.55 & -1.25 & $\begin{array}{l}\mathrm{E} \quad 09^{\circ} \\
14.4^{\prime \prime} \\
\mathrm{N} 118^{\circ} \\
48.4^{\prime \prime}\end{array}$ & & $\begin{array}{l}\text { Edge of } \\
\text { sea }\end{array}$ \\
\hline A & +1.63 & +2.18 & +0.38 & $\begin{array}{l}\text { Same } \\
\text { Point } \mathrm{O}\end{array}$ & as & $\begin{array}{l}\text { Next to } \\
\text { sea, } \\
\text { beginnin } \\
\text { g of earth } \\
\text { road }\end{array}$ \\
\hline C & +1.71 & +2.26 & +0.46 & $\begin{array}{l}\text { E } 09^{\circ} \\
14.0 " \\
\text { N } 118^{\circ} \\
49.9^{\prime \prime}\end{array}$ & $\begin{array}{l}44^{\prime} \\
43^{\prime}\end{array}$ & $\begin{array}{l}\text { Next to } \\
\text { houses, } \\
\text { level of } \\
\text { stilted } \\
\text { house } \\
\text { floor }\end{array}$ \\
\hline D & +0.31 & +0.86 & -0.94 & $\begin{array}{l}\text { Same } \\
\text { Point C }\end{array}$ & as & $\begin{array}{l}\text { Ground } \\
\text { beneath } \\
\text { houses } \\
\text { on stilts }\end{array}$ \\
\hline $\mathbf{E}$ & +2.31 & +2.86 & +1.06 & $\begin{array}{l}\mathrm{E} \quad 09^{\circ} \\
14.4^{\prime \prime} \\
\mathrm{N} 118^{\circ} \\
51.8^{\prime \prime}\end{array}$ & $\begin{array}{l}44^{\prime} \\
43^{\prime}\end{array}$ & $\begin{array}{l}\text { Road } \\
\text { adjacent } \\
\text { to village }\end{array}$ \\
\hline
\end{tabular}

Table 2 Summary of surveyed points at Barangay Manderagat. Survey started at $16^{\text {th }}$ March 2016 at 14:15

\begin{tabular}{|c|c|c|c|c|c|}
\hline $\begin{array}{l}\text { Poin } \\
t\end{array}$ & $\begin{array}{l}\text { Elevatio } \\
n(m) \\
\text { from sea } \\
\text { water }\end{array}$ & $\begin{array}{l}\text { Elevatio } \\
\mathbf{n}(\mathrm{m}) \\
\text { Correcte } \\
\text { d for tide } \\
\text { (Xtide) }\end{array}$ & $\begin{array}{l}\text { Elevatio } \\
\text { n }(\mathrm{m}) \\
\text { Correcte } \\
\text { d for } \\
\text { HHWL }\end{array}$ & $\begin{array}{l}\text { GPS } \\
\text { Coordinate } \\
s\end{array}$ & Notes \\
\hline A & +0.75 & +1.79 & -0.01 & 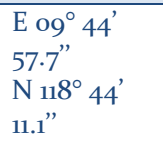 & $\begin{array}{l}\text { Pigster on } \\
\text { stilts at } \\
\text { the edge } \\
\text { of the sea }\end{array}$ \\
\hline B & +0.45 & +1.49 & -0.31 & $\begin{array}{l}{\mathrm{E} 09^{\circ} 44}^{\prime} \\
57.6^{\prime \prime} \\
\mathrm{N} 118^{\circ} 44^{\prime} \\
11.7^{\prime \prime}\end{array}$ & $\begin{array}{l}\text { Wooden } \\
\text { walkway } \\
\text { in } \\
\text { between } \\
\text { houses on } \\
\text { stilts }\end{array}$ \\
\hline C & +0.1 & +1.14 & -0.66 &  & $\begin{array}{l}\text { Bottom of } \\
\text { concrete } \\
\text { steps, just } \\
\text { above } \\
\text { water }\end{array}$ \\
\hline D & +0.46 & +1.50 & -0.3 & Same as $C$ & $\begin{array}{l}\text { Concrete } \\
\text { walkway } \\
\text { in } \\
\text { between } \\
\text { houses on } \\
\text { stilts }\end{array}$ \\
\hline $\mathbf{E}$ & +0.96 & +2.0 & +0.2 & 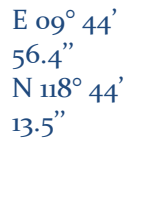 & $\begin{array}{l}\text { End of } \\
\text { informal } \\
\text { settlement } \\
\text { s and } \\
\text { houses on } \\
\text { stilts }\end{array}$ \\
\hline $\mathbf{F}$ & +3.36 & +4.40 & +2.6 & $\begin{array}{l}\mathrm{E} \mathrm{o9}^{\circ} 44^{\prime} \\
55.6^{\prime \prime} \\
N_{118^{\circ}} 44^{\prime} \\
14.5^{\prime \prime}\end{array}$ & $\begin{array}{l}\text { Road } \\
\text { towards } \\
\text { top of hill }\end{array}$ \\
\hline G & +8.06 & +9.10 & +7.3 & $\begin{array}{l}{\mathrm{E} 09^{\circ}}^{\circ} 44^{\prime} \\
54.5^{\prime \prime} \\
\mathrm{N} 118^{\circ} 44^{\prime} \\
15.4^{\prime \prime}\end{array}$ & $\begin{array}{l}\text { Top of } \\
\text { small hill } \\
\text { next to } \\
\text { informal } \\
\text { settlement }\end{array}$ \\
\hline
\end{tabular}




\section{Conclusion}

The methodology outlined in the present technical note should allow a sustainability scientist with limited financial resources to conduct a preliminary elevation survey of coastal areas, using equipment which is modest in cost and readily available. Point-bypoint bathymetric surveys are also possible, by lowering a surveying staff or a "rope and lead" into the water. While these methods are not a substitute for a professional survey, they can provide just enough information for sustainability scientists to solve a variety of preliminary research problems and initial planning related to a range of coastal issues and problems.

\section{Acknowledgments}

The authors wish to thank the participants of the UNCTAD expert level meeting on "Climate Change impacts and Adaptation for Coastal Transport Infrastructure in Caribbean SIDS" (29th to 1st of July 2016) for ideas, input, and review. Particularly, the role of Regina Asariotis in organizing this meeting together was instrumental in identifying the need for this technical note and bringing the authors together to write it.

\section{References}

[1] Asariotis R, Benamara H (eds) (2012) Maritime Transport and the Climate Change Challenge. Earthscan/Routledge, New York, NY

[2] Becker, A., Acciaro, M, Asariotis, R., Cabrera, E., Cretegny, L., Crist, P., Esteban, M., Mather, A., Messner, S., Naruse, S., Adolf K.Y., Stefan Rahmstorf, S., Savonis, M., Song. D. W., Stenek, V., Velegrakis, A. F. (2013) "A note on climate change adaptation for seaports: A challenge for global ports, a challenge for global society", Journal of Climatic Change DOI 10.1007/s10584-013-0843-z

[3] Esteban., M., Takagi and Shibayama, T. (2016) "Adaptation to an increase in typhoon intensity and sea-level rise by Japanese ports", Climate Change and Adaptation Planning for Ports. Ng., A. K. Y., Becker, A., Cahoon, S., Chen, S. L., Earl, P., and Yang, Z. (eds.) pp 117132

[4] Esteban, M.. Takagi, H. and Nguyen D. T. (2014) "Tropical Cyclone Damage to Coastal Defenses: Future Influence of Climate Change and Sea Level Rise on Shallow Coastal Areas in Southern Vietnam", In Coastal Disasters and Climate Change in Vietnam: Engineering and Planning Perspectives, Nguyen D. T., Takagi, H. and Esteban, M. editors, Elsevier, Amsterdam.

[5] Esteban, M., Webersik, C., Shibayama, T. (2009) "Methodology for the Estimation of the Increase in Time Loss Due to Future Increase in Tropical Cyclone Intensity in Japan", Journal of Climatic Change, Volume 102 (3) pp. 555-578,

[6] Hallegatte S, Ranger N, Mestre O, Dumas P, Corfee-Morlot J, Herweijer C, Wood RM (2011) Assessing climate change impacts, sea level rise and storm surge risk in port cities: a case study on Copenhagen. Climatic change 104 (1):113-137

[7] Hanson S, Nicholls RJ (2012) Extreme flood events and port cities through the twenty-first century. In: Asariotis R, Benemara, H. (ed) Maritime Transport and the Climate Change Challenge. Earthscan/Routledge, New York, NY, p 243

[8] Haveman JD, Shatz HJ (2006) Protecting the nation's seaports: Balancing security and cost. http://www.ppic.org/content/pubs/report/r_6o6jhr.pdf.

[9] Knutson, T. R., McBride, J. L., Chan, J., Emanuel. K., Holland, G., Landsea, C., Held, I., Kossin, J. P., Srivastava, A. K. \& Sugi, M. [2010] "Tropical cyclones and climate change," Nat Geos. 3, 157-163.

[10] Lloyds Loading List (2012) US Port Strike Ends. http://www.lloydsloadinglist.com.

[11] Nakamura, R., Shibayama, T., Esteban, M. and Iwamoto, T. (2016) "Future Typhoon and Storm Surges Under Different Global Warming Scenarios: Case Study of Typhoon Haiyan (2013)", Natural Hazards, Vol. 82 (3) pp. 1645-1681.
[12] Tebaldi C, Strauss BH, Zervas CE (2012) Modelling sea level rise impacts on storm surges along US coasts. Environmental Research Letters 7 (1):014032

[13] United Nations Conference on Trade and Development (2012) Review of Maritime Transport, 2012.

[14] United States Climate Change Science Program (2008) Impacts of Climate Change and Variability on Transportation Systems and Infrastructure: Gulf Coast Study, Phase I. Transportation Do. http://www.climatescience.gov/Library/sap/sap4-7/finalreport/.Vermeer M, Rahmstorf S (2009) Global sea level linked to global temperature. Proceedings of the National Academy of Sciences $106(51): 21527$

[15] Von Storch H, Gönnert G, Meine M (2008) Storm surges-An option for Hamburg, Germany, to mitigate expected future aggravation of risk. Environmental Science \& Policy 11 (8):735-742 